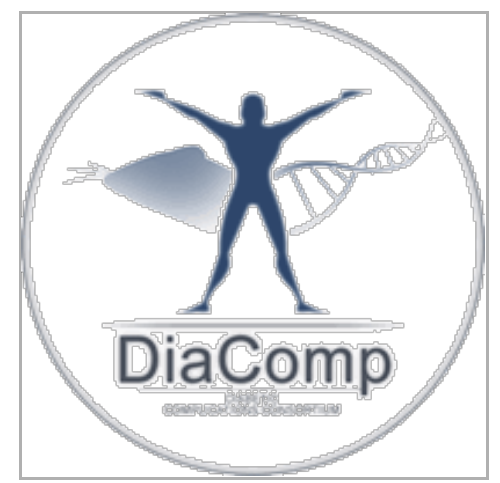

VERSION 2

OCT 18, 2019

\section{open $\partial$ ACCESS}

DOI:

dx.doi.org/10.17504/protocol s.io.8e4htgw

\section{External link:}

https://diacomp.org/shared/do cument.aspx?

id $=252 \&$ docType $=$ Protocol

\section{Protocol Citation: lan}

Simpson 2019. Restoration of euglycemia in the RCS10 mice with Metformin. protocols.io https://dx.doi.org/10.17504/p rotocols.io. $8 \mathrm{e} 4 \mathrm{htgw}$

License: This is an open access protocol distributed under the terms of the Creative Commons Attribution License, which permits unrestricted use, distribution, and reproduction in any medium, provided the original author and source are credited

Protocol status: Working We use this protocol and it's working

Created: Oct 18, 2019

Last Modified: Oct 18, 2019

\title{
(3) Restoration of euglycemia in the RCS10 mice with Metformin V.2
}

\author{
Ian Simpson ${ }^{1}$ \\ ${ }^{1}$ Pennsylvania State University \\ Diabetic Complications Consortium \\ Tech. support email: rmcindoe@augusta.edu
}

Lili Liang

\section{ABSTRACT}

\section{Summary:}

In this series of studies we wished to determine whether Metformin was able to establish and maintain euglycemia in RCS10 mice and would reduce infarct volume following a stroke. Metformin is a widely prescribed agent to treat Type II diabetes and as illustrated in Figure 2, when Metformin (0.8-1.3 g/ $\mathrm{kg} / \mathrm{D}$ ) is included in the water, it is able to establish and maintain euglycemia in the RCS10 mice over a 4week period. However, as illustrated in in Figure 3, restoration of euglycemia with metformin did not improve ischemic outcome.

\section{Diabetic Complications:}

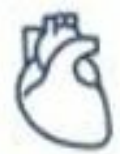

Cardiovascular

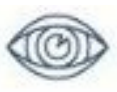

Retinopathy

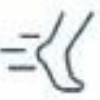

Neuropathy Nephropathy

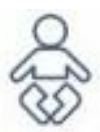

Pediatric Endocrinology

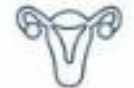

Uropathy

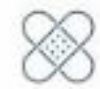

Wound-Healing

PROTOCOL integer ID: 28860 
Keywords: euglycemia, RCS10 mice, Metformin, cardiovascular, retinopathy, neuropathy, nephropathy, pediatric endocrinology, uropathy, wound-healing
MATERIALS

MATERIALS

88 Metformin Sigma Aldrich

$\$ 8$ saccharin Fisher Scientific

Note:

Thermo Fisher Scientific (RRID:SCR_008452)

Sigma-Aldrich (RRID:SCR_008988)

1 The Metformin was administered to the mice in their water to which $0.15 \%$ saccharin was added to ensure that mice consumed sufficient metformin/water to normalize their blood sugar (0.8-1.3 $\mathrm{g} / \mathrm{kg} / \mathrm{D}$ ). The saccharin levels in the water of control mice were diluted to normalize saccharin consumption. Figure 3 describes the effects of the Metformin on stroke outcome, which was determined at $48 \mathrm{~h}$ after the infarct by $\mathrm{H} / \mathrm{E}$ staining as described in the earlier report. These results in some respects are disappointing as our expectations were that the metformin would elicit a comparable effect to that we had obtained when euglycemia was induced in the $o b / o b$ mouse with darglitazone, a ppar $\gamma$ agonist. In that study, darglitazone not only normalized the bloodglucose levels it dramatically reduced the infarct volume in both diabetic and non- diabetic animals. The data described in Figure 3 is comparable to that obtained by (Tureyen et al., 2007) who found that Metformin treatment in the $d b / d b$ mouse had no effect on stoke outcome. However, in those studies the $d b / d b$ mice were too insulin- resistant to fully restore euglycemia and thus the observations were always considered equivocal. It should also be noted that the levels of Metformin used in this study and that of Tueyen et al. is significantly higher on a $\mathrm{mg} / \mathrm{kg}$ basis than used in patients, suggesting marked difference in sensitivity between rodents and humans which was not the case with the ppar $y$ agonists. This represents a very important observation that will lead willalter the scope of the RO1 resubmission as we will now not propose to investigate the mechanistic aspects of metformin but we have clearly demonstrated unlike the $d b / d b$ mice the glycemic state in RCS10 can be modulated.

\section{Figure 2}


Effects of Metformin on Blood Glucose in RCS10 Mice

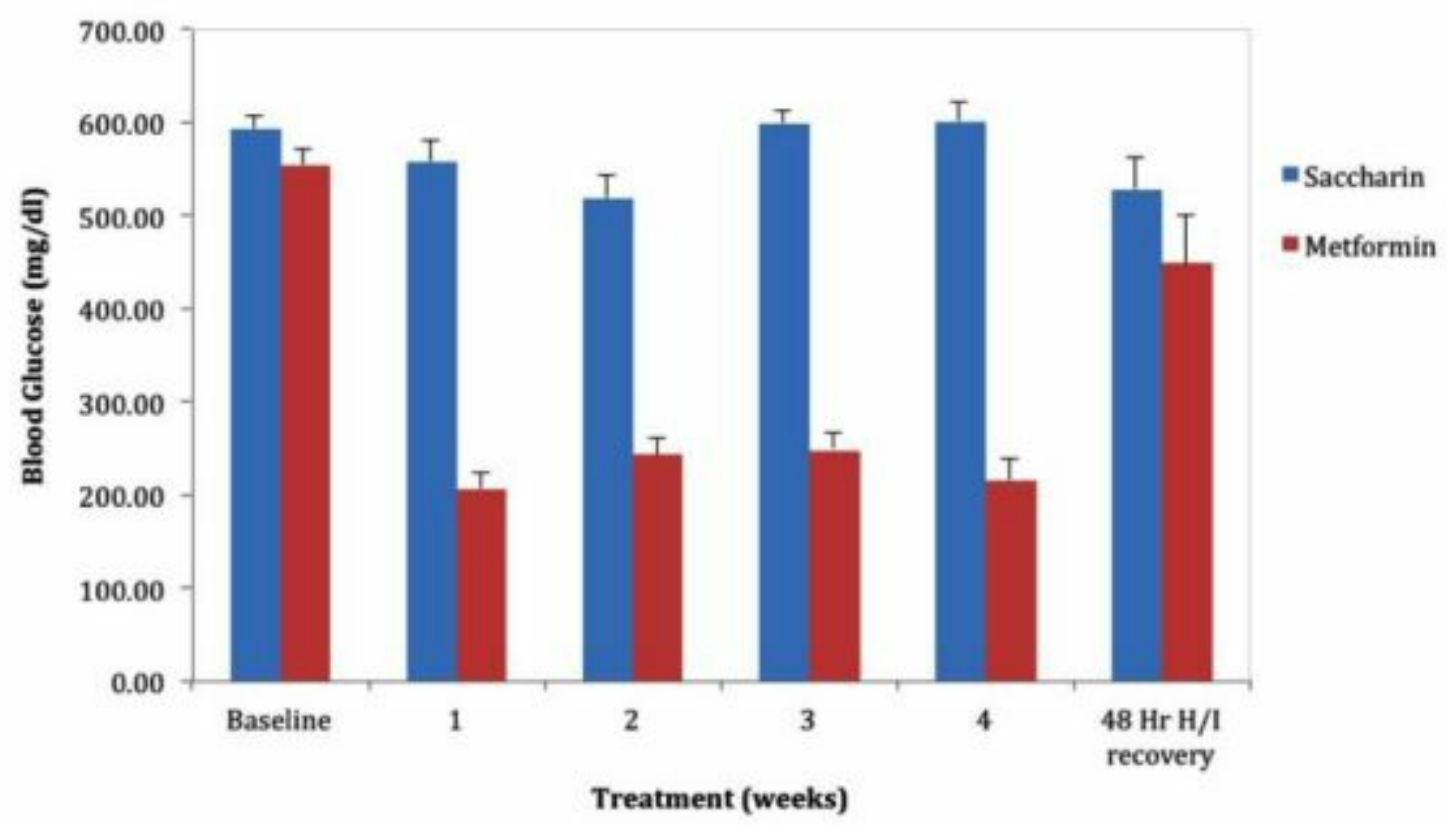

Figure 2 describes the time course for the normalization of blood glucose in the RCS10 mice. The RCS10 mice were 20 weeks old when Metformin treatment was initiated and had been diabetic for at least 4 weeks To maintain euglycemia the Metformin concentration in the drinking water was increased from $100-120 \mathrm{mg} / \mathrm{ml}$ over the course of the 4 weeks. $0.15 \%$ saccharin was added to mask Metformin and the concentrations were adjusted to ensure equal saccharin intake in the control RCS10 mice. The Metformin was unable to maintain euglycemia following the stroke presumably due to elevated corticosterone and consequent increased insulin resistance. 
Figure 3

\section{Effect of Metformin on Stroke Outcome \\ in RCS10 mice}

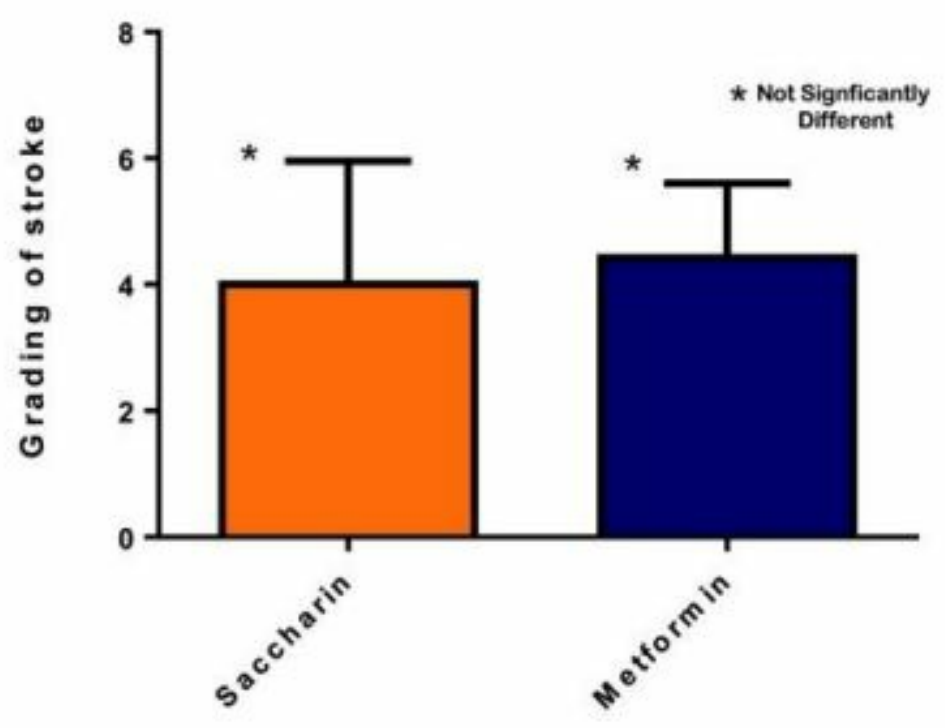

Figure 3 illustrates the effects of maintaining RCS10 mice euglycemic for four weeks on the subsequent outcome following stroke in the mice maintained as described in Figure 2. Both sets of animals were exposed to $22 \mathrm{~min}$ of $9 \%$ oxygen. The extent of the stroke damage was determined at $48 \mathrm{~h}$ post stroke infarct from H\&E sections as illustrated in earlier report. $(n=8$, Saccharin control mice and $n=15$, Metformin mice). There was no significant difference in the extent of the insult between the diabetic and euglycemic mice. 